\title{
Primary breast carcinoma with features of the follicular variant of papillary thyroid carcinoma
}

\author{
Nektarios Koufopoulos*1, Kasiani Anastasia Kapatou ${ }^{1}$, Foteini Antoniadou ${ }^{1}$, Dimitrios K Nasikas ${ }^{2}$, loannis \\ Karaitianos ${ }^{2}$, Stefania Kokkali ${ }^{3}$, Despoina Nasi ${ }^{1}$, Lubna Khaldi ${ }^{1}$ \\ ${ }^{1}$ Pathology Department, "Saint Savvas" Anti-Cancer Hospital, Athens, Greece \\ ${ }^{2}$ Surgery Department, "Saint Savvas" Anti-Cancer Hospital, Athens, Greece \\ ${ }^{3}$ Oncology Department, "Saint Savvas" Anti-Cancer Hospital, Athens, Greece
}

Received: November 30, 2017

DOI: $10.5430 /$ jst.v8n1p32
Accepted: January 1, $2018 \quad$ Online Published: January 11, 2018

URL: https://doi.org/10.5430/jst.v8n1p32

\begin{abstract}
A 61-year-old female patient with no previous medical history presented to our hospital with a palpable right breast mass as well as palpable axillary lymph nodes. Microscopic examination revealed a bifocal primary carcinoma of the breast displaying characteristics similar to that of follicular variant of papillary thyroid carcinoma. Three axillary lymph nodes contained metastases. Immunohistochemical study for TTF-1, Thyroglobulin, GATA-3, ER and PR was consistent with a primary breast carcinoma, excluding the possibility of a metastatic tumor.

The above unusual morphological features were caused by improper fixed tissue. Suboptimal fixation may cause tissue artifacts such as shrinkage, streaming, diffusion, vacuolation and nuclear or cytoplasmic changes as well as decreasing tissue antigenicity. Occasionally, altered morphology may mislead to major diagnostic pitfall.
\end{abstract}

Key Words: Breast carcinoma, Papillary thyroid carcinoma, TTF-1, Improper fixation, Artifact

\section{INTRODUCTION}

Carcinoma No Special Type (NST) is the most common type of breast adenocarcinoma accounting for $40 \%-75 \%$ of cases in published series. It is essentially a diagnosis of exclusion, defined by the lack of specific morphological features of special type carcinomas. Histologically it can display any architectural pattern. The tumor cells may be arranged in cords, clusters or trabeculae while some tumors are characterized by solid growth pattern. Cytological atypia may range from minimal to severe. Mitotic activity count could be very low or extremely high depending on the degree of differentiation. ${ }^{[1]}$
Papillary thyroid carcinoma (PTC) is the most common primary thyroid malignancy, considered as a malignant epithelial tumor with follicular cell differentiation, characterized histologically by certain nuclear characteristics which define the diagnosis. ${ }^{[2]}$ Usually displays an indolent clinical behavior remaining localized to the thyroid. Its metastatic spread commonly involves regional lymph nodes. Hematogenous metastases are uncommon, the most usual sites of involvement being the lung followed by the bone. ${ }^{[3]}$ In the English literature few cases of PTC metastasizing to the breast have been reported. ${ }^{[4-9]}$

Fixation is a complex series of chemical events that allow

\footnotetext{
*Correspondence: Nektarios Koufopoulos; Email: koufonektar@yahoo.com; Address: Pathology Department, “Saint Savvas” Anti-Cancer Hospital, Athens, Greece.
} 
tissues to be examined as close as possible to their living state and simultaneously to preserve DNA, mRNA and other biomolecules.

Suboptimal fixation may cause alteration of protein structure, shrinkage of tissue and/or brittle tissue; as a result major diagnostic problems may occur.

We herein report a case of a primary breast carcinoma NST that combines a follicular-like architectural pattern with the nuclear characteristics of PTC.

\section{Case presentation}

A 61-year-old female patient with no previous medical history presented to our hospital with a palpable right breast mass together with palpable axillary lymph nodes. Clinical examination followed by FNA in breast and ipsilateral axilla was positive for malignancy. Imaging did not reveal any other organ involvement. All other paraclinical investigations including thyroid function were normal. A right modified radical mastectomy was performed.

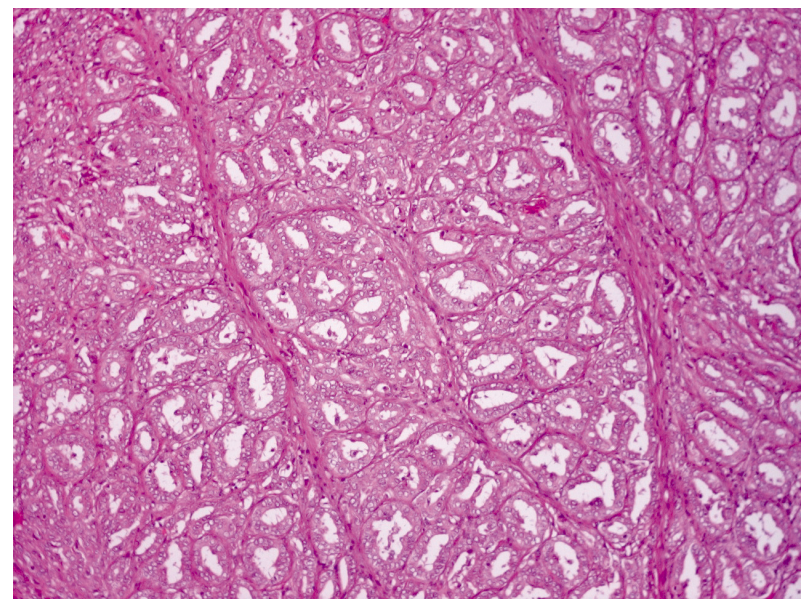

Figure 1. Round to ovoid glands divided into lobules by fibrous bands

Grossly a tumor consisting of two foci with a maximum diameter of $27 \mathrm{~mm}$ and $6 \mathrm{~mm}$ respectively was found within the lower medial quadrant of the right breast. On microscopic examination the larger neoplastic focus consisted mainly of closely opposed almost back to back round to ovoid glandular formations. Fibrous bands divided tumour into lobules (see Figure 1). Several intraluminal proliferations resembling glomeruloid structures were present (see Figure 2). The smaller neoplastic focus consisted of irregular glands and small tumor islands. Both lesions were composed of highly atypical cuboidal cells with irregular nuclear contour and eosinophilic cytoplasm. Nuclear overlapping finely dispersed optically clear chromatin and few nuclear grooves

Published by Sciedu Press were also noted (see Figure 3). In situ component either ductal or lobular was not identified. Mitotic figures were few in number. The tumor invaded the pectoralis muscle. Three out of twelve axillary lymph nodes contained metastases.

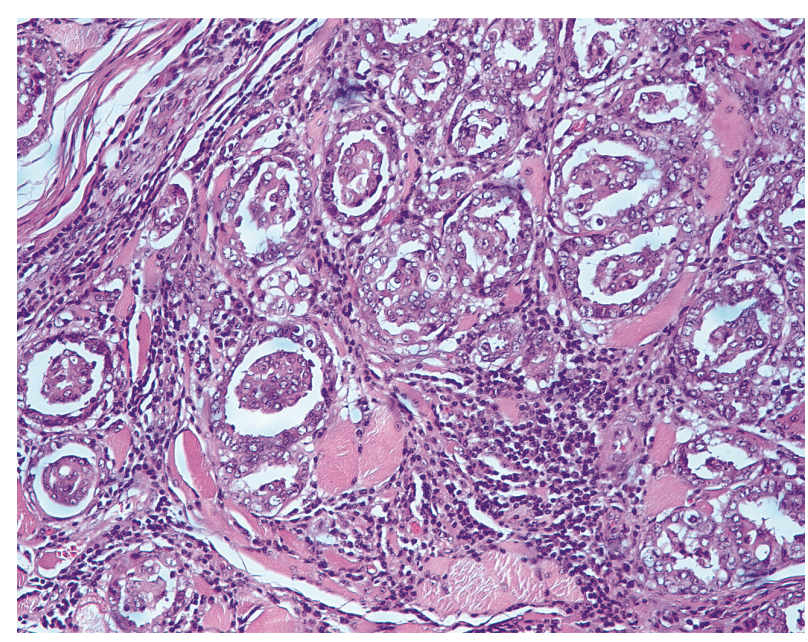

Figure 2. High power examination several intraluminal proliferations resembling glomeruloid structures invading striated muscle are visible

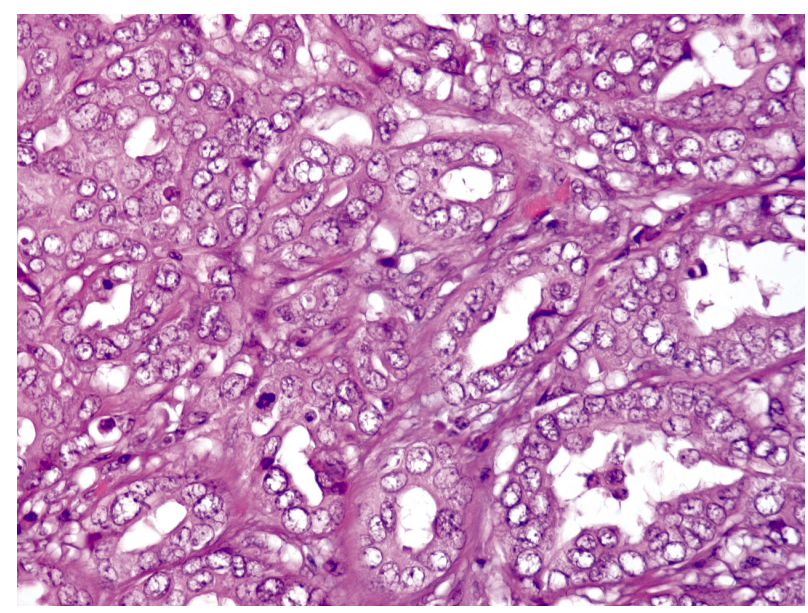

Figure 3. Tumor nuclei display overlapping, finely dispersed optically clear chromatin and few grooves reminding the nuclear characteristics of papillary thyroid carcinoma

The overall tumor morphology was similar to that of follicular variant of papillary thyroid carcinoma.

Immunochistochemical study was positive for GATA-3 (see Figure 4) and negative for TTF-1 and thyroglobulin. Tumor cells were strongly positive for estrogen and weakly positive for progesterone receptors and negative for HER-2 and Ki-67 index was $30 \%$. Staining with anti-smooth muscle actin and p63 confirmed the absence of an in situ component. The 
diagnosis of a multifocal carcinoma of the breast NST grade II was made.

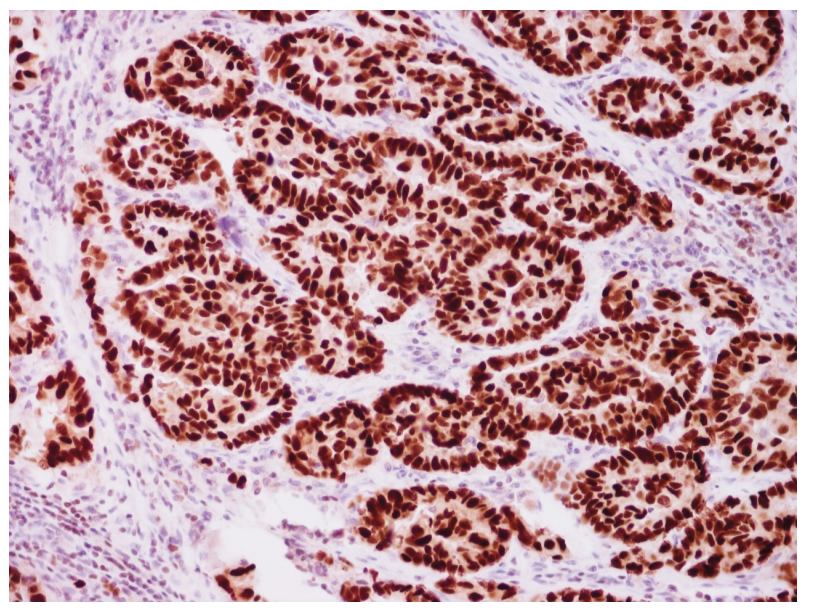

Figure 4. Immunohistochemical staining for GATA-3 shows diffuse, strong, nuclear staining

The patient received systemic adjuvant therapy and radiotherapy. Twenty-four months after surgery she is alive with no evidence of recurrence or metastasis.

\section{Discussion}

Metastatic neoplasms constitute $0.5 \%-2 \%$ of breast tumors. ${ }^{[1]}$ Mammary metastases from PTC are extremely rare. To the best of our knowledge there are only six cases of metastatic PTC reported in the English literature. ${ }^{[4-9]}$ PTC metastasis to the mammary gland is usually associated with disseminated disease ${ }^{[3]}$ Specifically, two cases of PTC follicular variant were found in the English literature exhibiting limited spreading. The first showed three cutaneous lesions and one breast metastasis, identified through a period of 11 years without any evidence of local recurrence or other sites of dissemination. ${ }^{[5]}$ The second presented with an isolated breast metastasis in a male patient ${ }^{[8]}$

Clinical examination by itself offers little help to define whether a breast tumor is primary or metastatic since the later may manifest breast lump with axillary lymph node involvement. ${ }^{[10]}$

In the present case the tumor revealed resemblance to the follicular variant of PTC with overall architecture and nuclear features suggestive of such.

Circumstantially, the differential diagnosis include mammary carcinoma NST, breast tumor resembling the tall cell variant of papillary thyroid carcinoma (BTPTC) and metastatic disease from thyroid.

High grade breast carcinoma may have similar nuclear features but the combination of extensive glandular formation with high grade atypia is unusual in primary mammary carcinomas. Furthermore, the absence of in situ component complicates the distinction between primary or metastatic tumor, which is a very helpful clue to resolve problematic cases when metastatic disease is suspected.

BTPTC is a very rare neoplasm initially described by Eusebi et al. ${ }^{[10]}$ Eversince a total of twenty six cases were reported in the English literature ${ }^{[10-16]}$ Histologically presenting features reminiscent thyroid follicles composed of neoplastic cells that display mostly solid to papillary architecture with areas of glandular-like formation which are filled by amorphous eosinophilic colloid-like material showing scalloped borders. Some of the tumors show abundant psammoma bodies and small aggregates of granular calcifications both within the glandular lumina and within the proliferating epithelium. The neoplastic cells range from columnar to cuboidal with eosinophilic granular cytoplasm and moderately pleomorphic ovoid nuclei some with clear chromatin. Angulated nuclear membrane borders and numerous grooves were seen in all cases; occasional eosinophilic pseudo-inclusions delimited by a rim of nuclear membrane were present in some of the cases. ${ }^{[16]}$

The case in hand lacks most of BTPTC's characteristics, such as papillary formations, thyroid-like follicular structures, columnar cells, pseudo-inclusions, psammoma bodies or granular calcifications. Additionally, immunohistochemical study for GATA-3, ER, PR, TTF-1 and Thyroglobulin ruled out the possibility of metastasis. Therefore the diagnosis of a primary breast carcinoma was made.

Finally, another interesting feature was present in our case that of glomeruloid structures. Such structures were described in acinar prostatic adenocarcinoma which were associated with high grade adenocarcinoma mainly grade 4 being considered as an early form of cribriform pattern. ${ }^{[17]}$ One may assume that the same is probably valid for breast carcinomas. Furthermore, glomeruloid features have also been described in single case reports of well differentiated papillary mesothelioma ${ }^{[18]}$ and follicular thyroid carcinoma. ${ }^{[19]}$

Taking in account the above all results and seeking the cause of the aforementioned morphology the authors realized that the tissue was improperly fixed. The specimen had been delayed for three days to reach the pathology department; it was cramped in a small pot with modicum fixative. Subsequently the specimen was handled macroscopically two days later.

Fixation is a chemical process in which tissue autolysis and putrefaction are arrested. Proper fixation depends on specimen thickness, volume of fixative and duration of fix- 
ation. Suboptimal fixation is disruption any and/or all of these parameters resulting (delayed or inadequate fixation). Improper/suboptimal fixation may induce tissue shrinkage, streaming, diffusion, vacuolation as well as nuclear clearing. Other changes of nucleus or cytoplasm displayed as altered staining quality, cell shrinking with cytoplasmic clumping, faint of nuclear chromatin and invisible nucleoli. Finally, loss of detail of vascular, nerves and glands structures may be observed. ${ }^{[20,21]}$

Prolonged fixation may cause "bleaching artifact" giving an empty space appearance simulating sometimes vascular invasion. ${ }^{[22]}$ Consequently, antigenicity may also be decreased, ${ }^{[23]}$ probably due high $\mathrm{pH}$ level of formalin solution, fortunately, immunostainning was not affected in the under

\section{REFERENCES}

[1] Lakhani SR, Ellis IO, Schnitt SJ, et al. WHO classification of tumors of the Breast. 2012. 34-5 p.

[2] Delellis RA, Lloyd RV, Heitz PU, et al. WHO classification of tumors of the endocrine organs. 2004. 57-9 p.

[3] Song HJ, Xue YL, Qiu ZL, et al. Uncommon metastases from differentiated thyroid carcinoma. Hell J Nucl Med. 2012; 15(3): 233-40. PMid:23106056

[4] Tan PK, Chua CL, Pob WT. Thyroid papillary carcinoma with unusual breast metastasis. Ann Acad Med Singapore. 1991; 20: 801-2. PMid:1803974

[5] Loureiro MM, Leite VH, Boavida JM, et al. An unusual case of papillary carcinoma of the thyroid with cutaneous and breast metastases only. Eur J Endocrinol. 1997; 137: 267-9. PMid:9330591 https://doi.org/10.1530/eje.0.1370267

[6] Fiche M, Cassagnau E, Aillet G, et al. Breast metastasis from a "tall cell variant" of papillary thyroid carcinoma. Ann Pathol. 1998; 18 : 130-2. PMid:9608866

[7] Angeles-Angeles A, Chable-Montero F, Martinez-Benitez B, et al. Unusual metastases of papillary thyroid carcinoma: report of 2 cases. Ann Diagn Pathol. 2009; 13: 189-96. PMid:19433299 https://doi.org/10.1016/j. anndiagpath. 2008.02.010

[8] Parasuraman L, Kane SV, Pai PS, et al. Isolated Metastasis in Male Breast from Differentiated Thyroid Carcinoma - Oncological Curiosity. A Case Report and Review of Literature. Indian J Surg Oncol. 2016; 7(1): 91-4. PMid:27065690 https://doi.org/10.1007/ s13193-015-0458-0

[9] Nusrath S, Mahagan M, Rao TS, et al. Follicular variant of Papillary Thyroid Cancer with Breast Metastasis. Indian J Surg Oncol. 2016; 7(3): 356-8. PMid:27651701 https://doi.org/10.1007/s131 93-016-0496-2

[10] Eusebi V, Damiani S, Ellis IO, et al. Breast tumour resembling the tall cell variant of papillary thyroid carcinoma: report of 5 cases. Am J Surg Pathol. 2003; 27: 1114-8. PMid:12883243 https: //doi.org/10.1097/00000478-200308000-00008

[11] Cameselle-Teijeiro J, Abdulkader I, Barreiro-Morandeira F, et al. Breast tumor resembling the tall cell variant of papillary thyroid carcinoma: a case report. Int J Surg Pathol. 2006; 14(1): 79-84. discussion case.

\section{Conclusion}

We present a case of primary breast carcinoma combining a follicular-like architectural pattern with the nuclear characteristics of PTC. Despite its resemblance to follicular variant of papillary thyroid carcinoma thorough histological examination and use of appropriate immunohistochemical markers contributed to correct diagnosis. Lastly but not least, suboptimal fixation should not be excluded from the differential diagnosis of analogous cases.

\section{CONFLicts OF INTEREST Disclosure}

The authors declare that there is no conflict of interest statement.
PMid:16501842 https://doi.org/10.1177/10668969060140 0116

[12] Tosi AL, Ragazzi M, Asioli S, et al. Breast Tumor Resembling the Tall Cell Variant Of Papillary Thyroid Carcinoma: Report of 4 Cases With Evidence Of Malignant Potential. Int J Surg Pathol. 2007; 15: 14-9. PMid:17172492 https://doi .org/10.1177/1066896906 295689

[13] Chang SY, Fleiszer DM, Mesurolle B, et al. Breast tumor resembling the tall cell variant of papillary thyroid carcinoma. Breast J. 2009; 15(5): 531-5. PMid:19594763 https://doi.org/10.1111/j.15 24-4741.2009.00773.x

[14] Masood S, Davis C, Kubik MJ. Changing the term "breast tumor resembling the tall cell variant of papillary thyroid carcinoma" to "tall cell variant of papillary breast carcinoma". Adv Anat Pathol. 2012; 19: 108-10. PMid:22313838 https://doi.org/10.1097/ PAP. 0b013e318249d090

[15] Colella R, Guerriero A, Giansanti M, et al. An additional case of breast tumor resembling the tall cell variant of papillary thyroid carcinoma. Int J Surg Pathol. 2015; 23(3): 217-20. PMid:24868004 https://doi.org/10.1177/1066896914536222

[16] Foschini MP, Asioli S, Foreid S, et al. Solid Papillary Breast Carcinomas Resembling The Tall Cell Variant of Papillary Thyroid Neoplasms: A Unique Invasive Tumor With Indolent Behavior. Am J Surg Pathol. 2017; 41(7): 887-95. PMid:28418993 https: //doi.org/10.1097/PAS.0000000000000853

[17] Minardi D, Mazzucchelli R, Scarpelli M, et al. Prostate cancer glands with cribriform architecture and with glomeruloid features should be considered as Gleason pattern 4 and not pattern 3. Future Oncol. 2016 Jun; 12(12): 1431-3. PMid:27189718 https: //doi.org/10.2217/fon-2016-0113

[18] Martínez-Consuegra N, Mu-oz-Juárez M, Ortiz-Hidalgo C. Unusual multifocal glomeruloid pattern in a well-differentiated papillary mesothelioma of the peritoneum. Int J Surg Pathol. 2008 Oct; 16(4): 426-7. PMid:18480398 https://doi.org/10.1177/10668969 08318450

[19] Cameselle-Teijeiro J, Pardal F, Eloy C, et al. Follicular thyroid carcinoma with an unusual glomeruloid pattern of growth. Hum Pathol. 2008 Oct; 39(10): 1540-7. PMid:18602667 https ://doi .org/10 $.1016 / j$. humpath.2008.01.014 
[20] Khan S, Tijare M, Jain M, et al. Artifacts in Histopathology: A Potential Cause of Misinterpretation. RRJDS. 2014; 2(2): 23-31.

[21] Chatterjee S. Artefacts in histopathology. Journal of Oral and Maxillofacial Pathology: JOMFP. 2014; 18(Suppl 1): S111-6. PMid:25364159 https://doi .org/10.4103/0973-029X.1413 46
[22] Jimson S, Malathi L, Kumar GMK, et al. Artifact in Histological Section. Biomed Pharmacol J. 2016; 9(2).

[23] Webster JD, Miller MA, Dusold D, et al. Effects of prolonged formalin fixation on diagnostic immunohistochemistry in domestic animals. J Histochem Cytochem. 2009; 57(8): 753-61. PMid:19398606 https://doi.org/10.1369/jhc. 2009.953877 